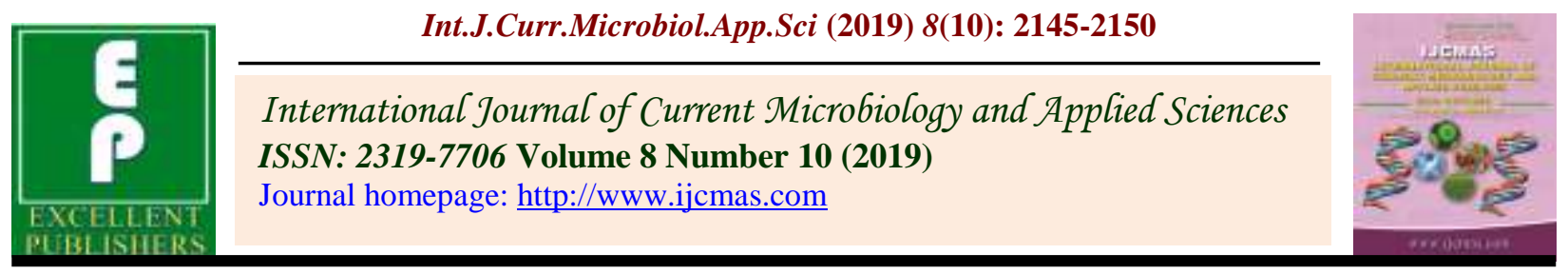

Original Research Article

https://doi.org/10.20546/ijcmas.2019.810.249

\title{
Expression of Bovine Viral Diarrhoea Virus E2 Gene in HeLa Cell Line
}

\author{
Nitin Sharma* and Mahesh Kumar
}

Division of Animal Cell Culture Laboratory, Institute of Biotechnology, G.B. Pant University of Agriculture \& Technology, Patwadangar (Nainital)-263128, UK, India

*Corresponding author

\section{A B S T R A C T}

Keywords

BVDV, E2,

Expression,

Eukaryotic system

Article Info

Accepted:

15 September 2019

Available Online:

10 October 2019
Bovine viral diarrhoea virus (BVDV) is the most prevalent infectious disease of cattle. The envelope glycoprotein (E2) gene of an Indian BVDV isolate was already cloned. In this study, recombinant plasmid pcDNA.BVDV.E2 was used to transfect $70-80 \%$ HeLa cell, expressed E2 protein which was confirmed by immunoperoxidase test. Rabit anti mouse HRPO conjugate was used in expression analysis and anti BVDV-E2 hyperimmune serum was raised in mice using recombinant plasmid pcDNA.BVDV.E2 for develop specific antibody. This study demonstrates feasibility of BVDV E2 protein expression in HeLa cell and its efficacy as an antigen in ELISA for detecting BVDV neutralizing antibodies in cattle.

\section{Introduction}

Bovine viral diarrhoea virus (BVDV) is a pestivirus in the family Flaviviridae and is closely related to classical swine fever and ovine Border disease viruses ${ }^{1}$. BVDV is a positive-sense, single-stranded nonpolyadenylated RNA virus about $12.5 \mathrm{~kb}$ in size with one large ORF flanked by $5^{\prime}$ and 3' NTRs. The virion is enveloped and spherical in shape with a diameter of 40-60 nm. Two antigenically distinct genotypes of BVDV exist, types 1 and 2, with further subdivisions discernable by genetic analysis ${ }^{2}$.The two genotypes may be differentiated from each other, and from other pestiviruses, by monoclonal antibodies (MAbs) directed against the E2 and ERNS major glycoproteins, or by genetic analysis ${ }^{3,4}$. Multiplex polymerase chain reaction (PCR) enables virus typing direct from blood samples $^{5}$. Type 1 virus is generally more common although the prevalence of type 2 is reported to be almost as high as type 1 in North America. BVDV of both genotypes may occur in noncytopathogenic and cytopathogenic forms (biotypes), classified according to whether or not it produces visible change in cell cultures. Usually, it is the noncytopathogenic biotype that circulates in 
cattle populations. Each biotype has a specific role in a variety of clinical syndromes- acute, congenital and chronic infections ${ }^{6,7}$. Type 2 viruses are usually noncytopathogenic and have been associated with outbreaks of severe acute infection and a haemorrhagic syndrome $^{8}$. However recent type 2 viruses isolated in the United Kingdom have been associated with a disease indistinguishable from that seen with the more frequently isolated type 1 viruses. Some type 1 isolates have been associated with particularly sever and fatal disease outbreaks in adult cattle ${ }^{9}$ clinically mild and in apparent infections are common with both genotypes.

Persistently viraemic healthy animals resulting from congenital infection can be readily identified by isolation of noncytopathogenic virus in cell cultures from blood or serum. It is necessary to use an immune-labelling method to detect the growth of virus in the cultures. Alternative methods based on direct detection of viral antigen or viral RNA in leukocytes are also available. Persistence of virus should be confirmed by resampling after an interval of at least 3 weeks. These animals will usually have no or low levels of antibodies to BVDV. Viraemia in acute cases is transient and can be difficult to detect. In fatal cases of haemorrhagic disease, virus can be isolated from tissues post-mortem. Confirmation of mucosal disease can be made by isolation of the cytopathogenic biotype of BVDV, particularly from intestinal tissues. Noncytopathogenic virus may also be detected, especially in blood.

The most common laboratory method for this purpose is enzyme-linked immunosorbent assay (ELISA) ${ }^{10}$. The most immunogenic proteins of $\mathrm{BVDV}^{11}$, including Erns and E2 structural proteins and the non-structural NS3 protein have been prepared as recombinant proteins and applied to design ELISAs for the detection of specific antibodies in cattle sera ${ }^{12}$.
The NS3 is an $80 \mathrm{kDa}$ (p80) protein which contains an $\mathrm{N}$-terminal serine protease domain and a C-terminal RNA helicase ${ }^{13}$. Production of NS3 is essential for the viral RNA replication and cytopathogenicity ${ }^{14}$. This protein is also highly conserved among pestiviruses and induces a strong humoral immune response in cattle exposed to live BVDV either naturally or by vaccination ${ }^{15}$. Therefore, it is a proper candidate antigen to detect antibodies against the virus in the sera of infected animals. For this purpose, NS3 and NS3-specific monoclonal antibodies (MAbs) were used to design ELISAs (indirect and competitive ELISA) for the detection of specific antibodies against the virus ${ }^{16,17,18}$. During the recent years, economic impact of BVDV infections has led a number of countries in Europe to start eradication or control programmes ${ }^{19,20}$. In Iran, the prevalence of BVDV antibodies in adult cattle is around $25.0 \%^{21,22}$. It is therefore desirable to have a rapid, sensitive and reliable means of identifying infected animals for control and eradication of BVD. Anti-NS3 MAbs were produced mainly following immunization with whole virus. The main objective of this study was to produce monoclonal antibody against recombinant NS3 antigen of BVDV that was produced in an efficient bacterial expression system to design a local competitive ELISA for detecting infected animals in future.

\section{Materials and Methods}

\section{Recombinant plasmid}

The recombinant plasmid pcDNA.BVDV.E2 was available in the Biotechnology Laboratory, IBT, patwadangar Nainital.

\section{Cell Line}

HeLa cell line was obtained from National centre for Cell Science (NCCS), Pune. HeLa cell line was used in the study for in vitro 
expression analysis of recombinant plasmids (pcDNA.BVDV.E2) and was maintained in GMEM (Micro lab), supplemented with 10\% new born calf serum (Gibco, NY), penicillin 100 units $/ \mathrm{ml}$ and streptomycin $100 \mu \mathrm{g} / \mathrm{ml}$.

\section{Virus}

Bovine viral diarrhoea viruses as well as BT cell culture adapted BDV were available in the laboratory.

\section{Conjugates and hyperimmune serum}

Direct polyclonal antibody conjugate rabbit anti-mouse HRPO obtained from Bangalore Genei, Bangalore, was used in expression analysis of pcDNA.BVDV.E2 and anti-BVDV E2 hyperimmune serum was raise in mice using recombinant plasmid (pcDNA.BVDV.E2). The recombinant plasmid $(50 \mu \mathrm{g} / \mathrm{mouse})$ was administered intramuscularly in thigh four times at interval of one week, to six mice. The bold was collected one week later from inner canthus of eye of the mouse and serum was harvested.

\section{In vitro expression analysis}

\section{Transfection of HeLa cells}

Cells were trypsinised using trypsin-versenate solution (TVS) and then $4 \mathrm{ml}$ of GMEM containing 10\% FCS and penicillin and streptomycin $(50 \mu \mathrm{l} / \mathrm{ml})$ was added, to make cell suspension of 1 X105 cells/ml. Harvested exponentially growing cells by trypsinization and prepared cell suspension in growth medium.

Prepared the calcium phosphate-DNA coprecipitate as follows: combined $50 \mu \mathrm{l}$ of $2.5 \mathrm{M} \mathrm{CaCl} 2$ with $10 \mu \mathrm{l}$ of plasmid DNA in a sterile microfuge tube. Added $40 \mu \mathrm{DW}$, kept at room temperature. Immediately transferred the calcium phosphate-DNA suspension using
$20 \mu \mathrm{l}$ suspension for each wells of microtitre plate. Added $100 \mu \mathrm{l}$ of cell culture suspension in each wells of 96 wells microtitter plate. Rocked the plate gently to mix the medium, which will become yellow-orange and turbid. Carried out this step as quickly as possible because the efficiency of transfection declines rapidly once the DNA precipitate is formed. Kept control wells without transfection.

Incubated at 370C in a humidified incubator with an atmosphere of $5 \% \mathrm{CO}_{2}$ for 72 hours. Examined for gene expression by IPT.

\section{Raising primary antibody against pcDNA.BVDV.E2 in mice}

Primary polyclonal antibody against the BVDV E2 gene was raised in mouse by hyper immunization of six mice with pcDNA.BVDV.E2 plasmid. 50 $\mu 1$ of plasmid DNA was injected IM rout in lateral region of thigh muscles of each mouse and repeated every week for four weeks consecutively. Mice were bled through inner canthus of eyes with a capillary and serum was prepared.

\section{Immunoperoxidase test (IPT)}

After 72 hours, transfected HeLa cells were washed with 1XPBS twice and fixed with $80 \%$ chilled acetone at $4^{0} \mathrm{C}$ for $10 \mathrm{~min}$ and airdried. Put a few drops of BVDV E2 hyperimmune serum and incubated at $37^{\circ} \mathrm{C}$ for $1 \mathrm{hr}$ and again washed with PBS, added a few drops of horseradish- peroxidase (HRPO) conjugated rabbit anti-mouse antibody to wells and incubated at $370 \mathrm{C}$ for $1 \mathrm{hr}$ in humid chamber.

The cells were again washed with PBS thrice and incubated with 2-3 drops of Nadi reagent for $5 \mathrm{~min}$. After the development of color, cells were washed with PBS, dried in air and observed under microscope and photographed, protocol was carried out as per $^{23}$. 


\section{Results and Discussion}

Bovine viral diarrhoea (BVD) is one of the most economically important infectious diseases in cattle worldwide and the causative agent, BVD Virus (BVDV) is a pestivirus in the family Flaviviridae. The E2 protein is the major target of the protective immune response elicited against BVDV infection.

\section{Expression of recombinant plasmid}

The expression ability of recombinant plasmids was checked by immunoperoxidase test (IPT) in HeLa cell line and cells were found to express the protein by development of purple color. Intense purple coloration of cells was observed in which HeLa cells were transfected with pcDNA.BVDV.E2 (Fig. 1), while healthy cell control did not show any color change.

E2 is a main component of the virions and, together with Erns and E1, forms the surface projections protruding from the viral envelope $^{24}$. In infected cells as well as in virions, it can be found as a homodimer of about $100 \mathrm{kDa}$ or, together with $\mathrm{E} 1$, as a heterodimer of about $75 \mathrm{kDa}$. Immunostaining of infected cells indicates that E2 and Erns are absent from the plasma membrane ${ }^{25,26,27}$. For expression in eukaryotic system pcDNA 3.1 vector was used which is a high level constitutive expression vector designed for use in variety of cells. This vector has CMV enhancer promoter, bovine growth hormone polyadenylation signals, transcription termination sequence and SV40 origin of episomal replication. The CMV promoter has been reported to be very strong promoter and has been used by many workers for high level expression. It has also been revealed that vectors containing the CMV promoter and bovine growth hormone termination signal works well in avian DNA vaccination ${ }^{28 .}$

Fig.1 HeLa cells transfected with recombinant plasmid pcDNA.BVDV.E2 and analysed with IPT showing purple color

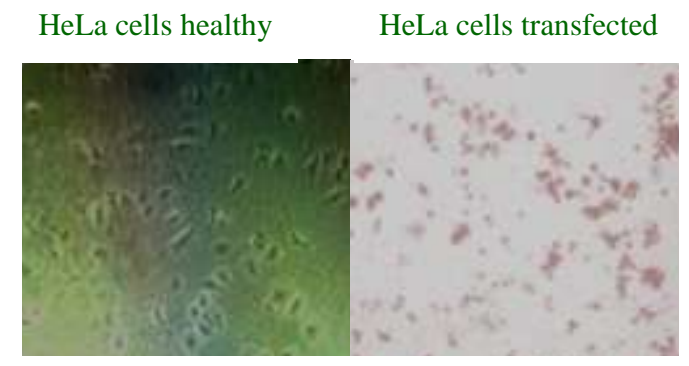

The cells were transfected with recombinant pcDNA.bdv.E2 plasmid by calcium phosphate method $^{29}$. In this method, uptake of DNA by cultured cells is enhanced when DNA is presented as a co-precipitate of calcium phosphate and DNA. Replacement of medium containing calcium phosphate with medium having $2-5 \%$ serum was found to reduce the toxicity of calcium phosphate co-precipitate to the cells ${ }^{30}$. This method of transfection has been reported to be better and also less toxic for established cell lines ${ }^{29,30}$. The results of the present study would be useful for the development of DNA vaccine against BVDV disease. 


\section{Acknowledgement}

Authors thank Director, IBT, Patwadangar, Nainital and also thank Director, IBIT Izatnagar, Bareilly for providing facilities to carry out this work.

\section{References}

Donis RO, Molecular biology of bovine viral diarrhea virus and its interactions with the host. Vet Clin North Am, 11 (1995) 393.

Vilcek S, Paton DJ, Durkovic B, Strojny L, Ibata G, Moussa A, Loitsh A, Rossmanith W, Vega S, Scicluna MT \& Palfi V, Bovine viral diarrhoea virus genotype 1 can be separated into at least eleven genetic groups. Arch Virol, 146 (2001) 99.

Pellerin C, Vandenhurk J, Lecomte J \& Tijssen P, Identification of a new group of bovine viral diarrhea virus strains associated with severe outbreaks and high mortalities. Virol, 203 (1994) 260.

Ridpath JF, Bolin SR \& Dubovi EJ, Segregation of bovine viral diarrhea virus into genotypes. Virol, 205 (1994) 66.

Gilbert SA, Burton KM, Prins SE \& Deregt D, Typing of bovine viral diarrhea viruses directly from blood of persistently infected cattle by multiplex PCR. $J$ Clin Microbiol, 37 (1999) 2020.

Bolin SR, The pathogenesis of mucosal disease. Vet Clin North Am, 11 (1995) 489.

Browlnie J, Clinical aspects of the bovine virus diarrhoea/mucosal disease complex in cattle. In Practice, 7 (1985) 195.

Carman S, Van Dreumel T, Ridpath J, Hazlett M, Alves D, Dubovi E, Tremblay R, Bolin S, Godkin A \& Anderson N, Severe acute bovine viral diarrhea in
Ontario, 1993-1995. J Vet Diagn Invest, 10 (1998) 27.

David GP, Crawshaw TR, Gunning RF, Hibberd RC, Lloyd GM \& Marsh PR, Severe disease in adult dairy cattle in three UK dairy herds associated with BVD virus infection. Vet Rec, 134 (1994) 468.

Sandvik T, Laboratory diagnostic investigations for bovine viral diarrhoea virus infections in cattle. Vet Microbiol, 64 (1999) 123.

Bolin SR, Immunogens of bovine viral diarrhea virus. Vet microbial, 37 (1993) 263.

Chimeno Zoth S, Taboga O, Multiple recombinant ELISA for the detection of bovine viral diarrhoea virus antibodies in cattle sera. $J$ Virol Methods, 138 (2006) 99.

Wiskerchen M, Collett MS, Pestivirus gene expression: Protein $\mathrm{p} 80$ of bovine viral diarrhea virus is a proteinase involved in polyprotein processing. Virol, 184 (1991) 341.

Agapov EV, Murray CL, Frolov I, Uncleaved NS2-3 is required for production of infectious bovine viral diarrhea virus. $J$ Virol, 78 (2004) 2414.

Bolin S, Ridpath J, Specificity of neutralizing and precipitating antibodies induced in healthy calves by monovalent modified-live bovine viral diarrhea virus vaccines. Am $\mathrm{J}$ Vet Res, 50 (1989) 817.

Lecomte C, Pin J, De Moerlooze L, ELISA detection of bovine viral diarrhoea virus specific antibodies using recombinant antigen and monoclonal antibodies. Vet Microbiol, 23 (1990) 193.

Reddy J, Kwang J, Okwumabua O, Application of recombinant bovine viral diarrhea virus proteins in the diagnosis of bovine viral diarrhea infection in cattle. Vet Microbiol, 57 
(1997) 119.

Beaudeau F, Belloc C, Seegers H, Evaluation of a blocking ELISA for the detection of bovine viral diarrhea virus (BVDV) antibodies in serum and milk. Vet Microbiol, 80 (2001) 329.

Greiser-Wilke I, Grummer B, Moennig V, Bovine viral diarrhoea eradication and control programmes in Europe. Biologicals, 31 (2003) 113.

Moennig V, Houe H, Lindberg A, BVD control in Europe: Current status and perspectives. Anim Health Res Rev, 6 (2005) 63.

Morshedi A, Mahmudian AR, Dalir Naqadeh $B$, Serological survey of cattle infected with BVD virus by indirect ELISA and comparison of the use of milk ELISA and serum ELISA in Urmia. $J F$ Vet Med, (Tehran University) 59 (2004) 227.

Haji K, Seyfiabad SM, Serological study of bovine viral diarrhea virus infection of cattle in Ahvaz. J Vet Res, 62 (2007) 21.

Nakane, PK and Kawaoi A, Peroxidurelabelled antibody: A new method of conjugate. J Histochem Cytochem, 22 (1974) 1084.

Thiel HJ, Stark R, Weiland E, Ru- menapf T \& Meyers G, Hog cholera virus: molecular composition of virions from a pestivirus. J Virol, 65 (1991) 4705.

Greiser-Wilke I, Dittmar KE, Liess B \& Moennig V, Immunofluorescence studies of biotype-specific expression of bovine viral diarrhoea virus epitopes in infected cells. $J$ Gen Virol, 72 (1991) 2015.

Grummer B, Beer M, Liebler-Tenorio E \& Greiser-Wilke I, Localization of viral proteins in cells infected with bovine viral diarrhoea virus. J Gen Virol, 82 (2001) 2597.

Weiland F, Weiland E, Unger G, Saalmuller A \& Thiel HJ, Localization of pestiviral envelope proteins Erns and E2 at the cell surface and on isolated particles. $J$ Gen Virol, 80 (1999) 1157.

Suarez DL and Schultz-Cherry S, The effect of eukaryotic expression vectors and adjuvants on DNA vaccines in chickens using an avian influenza model. Avian Diseases, 44 (2000) 861.

Sambrook J, Fritsch EF and Maniatis T, Molecular Cloning: A Laboratory manual (second edition). (Cold Spring Harbour Laboratory Press), 1989.

Graham FL and van der Eb AJ, A new technique for assay of infectivity of human adenovirus 5 DNA. Virol, 52 (1973) 456.

\section{How to cite this article:}

Nitin Sharma and Mahesh Kumar 2019. Expression of Bovine Viral Diarrhoea Virus E2 Gene in HeLa Cell Line. Int.J.Curr.Microbiol.App.Sci. 8(10): 2145-2150.

doi: https://doi.org/10.20546/ijcmas.2019.810.249 